\title{
Numerical study of the air distribution in the Crew Quarters on board of the International Space Station
}

\author{
Charles Berville ${ }^{1, *}$, Matei-Răzvan Georgescu ${ }^{1}$, and Ilinca Năstase ${ }^{1}$ \\ ${ }^{1}$ UTCB, Technical University of Civil Engineering in Bucharest, Building Services Department, 66 Avenue Pache Protopopesc; 020396, \\ Bucharest, Romania;
}

\begin{abstract}
The current concept of Crew Quarters on board of the International Space Station has several issues according to the crew member's feedback. Major issues concern noise levels, the accumulation of $\mathrm{CO}_{2}$ and the quality of the air distribution. Our study targets the airflow distribution, to diagnose this issue, we realise a series of numerical simulations (CFD) based on a real scale replica of the Crew Quarters. Simulations were set with a zero-gravity mode and with the theoretical air parameters inside the SSI. The geometry includes a thermal manikin having the neutral posture of a body in the absence of gravity. Numerical simulations were run for the three different air flow rates provided by the current ventilation system. Results have shown that the air distribution inside the Crew Quarter is insufficient for low airflow rates but becomes acceptable for the higher airflow rate, however the higher airflow rate can potentially produce draught discomfort.
\end{abstract}

\section{Introduction}

\subsection{Problematics}

This paper presents a study of the air quality within the International Space Station and more particularly inside the private cabins of crew members, called Crew Quarters. The current concept of Crew Quarters on board of the International Space Station has several issues according to the crew member's feedback. Major issues concern noises levels, the accumulation of $\mathrm{CO}_{2}$ and the quality of the air distribution [1]. Like all human beings, crew members need rest. Indeed, a good rest for the crew members is essential, because firstly there are only six members permanently on the International Space Station, and secondly, the tasks performed by crew members require increased concentration, so they must be in good health and efficient. It's for this purpose that the concept of the Crew Quarter was designed. The first private cabin developments planned for long-term crew travel began with the US Skylab Crew Quarter. A private place where crew members can rest. For a good rest, thermal comfort and air quality must be optimal, sources of noise must be negligible and finally the overall system must be energy efficient. For this, the air distribution system and sound insulation must be efficient, effective and compact.

Accumulation and re-breathing of $\mathrm{CO}_{2}$ in expired air has been investigated as a possible indication for crew discomfort onboard the International Space Station (ISS) [2]. Likewise, inadequate airflow contributes to increasing temperature that also leads to crew discomfort. Thus, the objective of this study is to establish an operational numerical model allowing the analysis of air distribution in the Crew Quarter.

\subsection{Study presentation}

Our study concerns the four Crew Quarters situated in the Node 2, also known as Harmony Module. The Harmony module is owned by the USA (United States On-orbit Segment - USOS) and links the European laboratory Columbus, the Japanese laboratory Kibô and the American laboratory Destiny. The four Crew Quarters are mirrored in front of one another and they were designed to fit inside the standard rack spaces present on the ISS (see Figure 1).

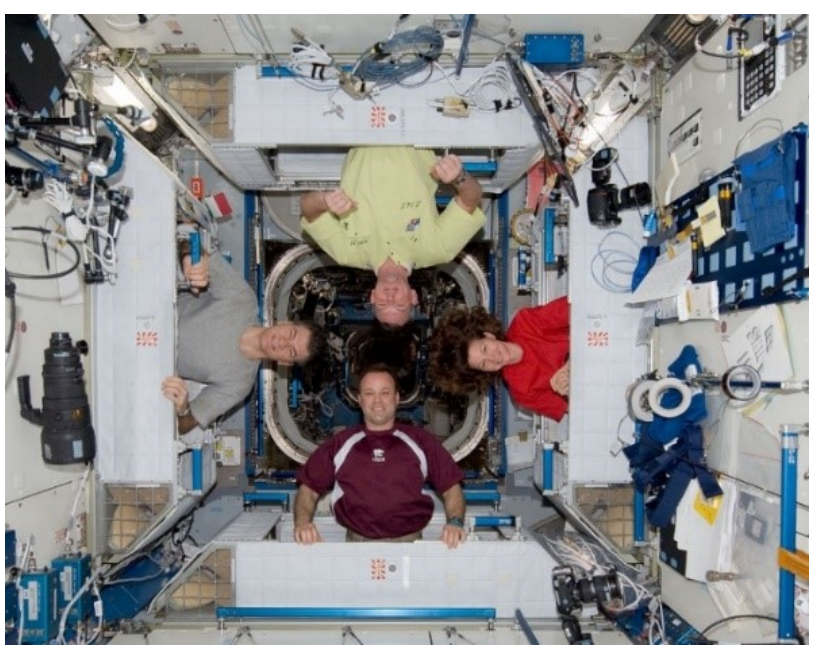

Fig. 1. Inside view of the Node 2 Harmony [6].

\footnotetext{
* Corresponding author: charles.berville@gmail.com
} 
Each Crew Quarter has an individual ventilation system including a push-pull fans system to ensure fresh air at the crew member's head position. The fan located in the intake duct pulls the air from Node 2 and pushes it in the Crew Quarter interior volume and the second fan pulls and pushes out the exhaust air. Consequently, the ventilation system can only increase the interior airflow rate to reduce the temperature difference between the Common Cabin Air Assembly (CCAA) and the Crew Quarter interior.

The air intake and exhaust directions are consistent with the general air flow of Node 2, which allows the CCAA smoke detector to identify combustion events in the Crew Quarter. It also minimizes the risk of recirculation of the exhaust air, which could be detrimental to a good cooling and air recycling inside the CQ $[1,3,4]$.

\section{Numerical model}

We realised a series of simulations for three different air flow rates corresponding to the three positions of the fan system inside the CQ (low, medium and high, respectively $108 \mathrm{~m} 3 / \mathrm{h}, 138 \mathrm{~m} 3 / \mathrm{h}$ and $156 \mathrm{~m} 3 / \mathrm{h}$ ). And we also compared three different configurations to observe the effects of considering the real speed profile and the heat flux generated by the crew member. Thus, we ran the three following simulation scenarios for the three different air flow rates provided by the fan system:

- Uniform speed profile and isothermal manikin;

- Measured velocity profile (real) and isothermal manikin;

- Measured velocity profile and anisothermal manikin.

In order to understand the flows occurring in the air diffusion system of the CQ, we have carried out a series of measurements in the replica of the Crew Quarter, along the inlet grid using a hot-ball anemometer. This allowed us to determine a non-uniform speed profile to model the air flow inside the CQ as real as possible. Then we introduced this speed profile in Fluent as an «Inlet velocity magnitude profile » by a User Defined Function (UDF).

\subsection{Geometry and manikin}

The geometrical model was realised in SolidWorks and then imported in Ansys Design Modeler. The geometrical model is based on the replica of the Crew Quarter built by our team and present at the Faculty of Building Services of Bucharest (see Figure 2).

Like the real CQ, the total deployed volume of the Crew Quarter replica is approximately $2.1 \mathrm{~m}^{3}$. Inside the geometrical model we introduced a thermal manikin having the theoretical posture of human body in a zerogravity environment [7]. The manikin is split into 9 zones with different temperatures.
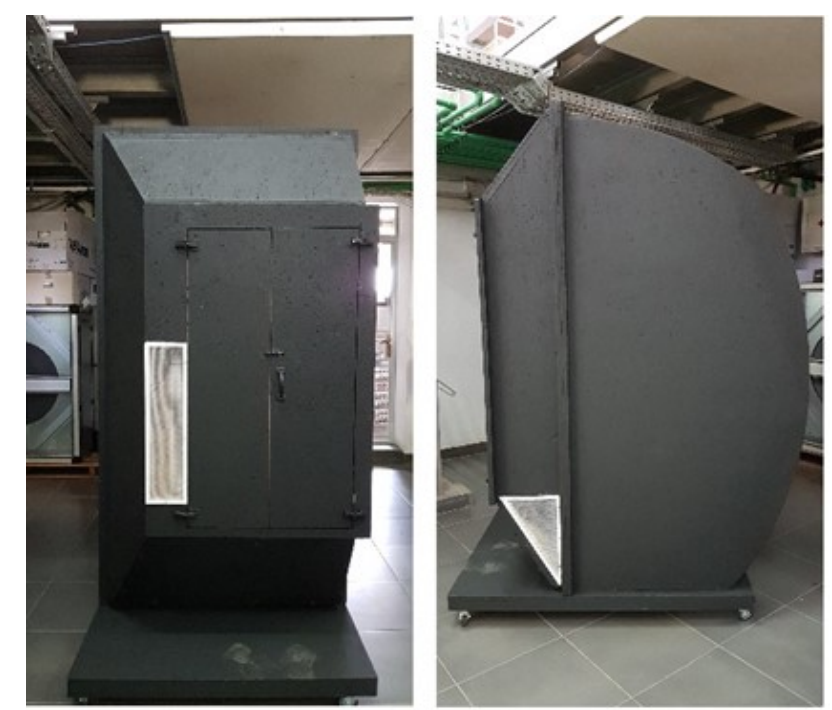

Fig. 2. Replica of the Crew Quarter.

The temperatures imposed on the manikin for the boundary conditions are as follows:

Tabel 1. Temperatures imposed on the manikin surface [8].

\begin{tabular}{|c|c|c|c|c|}
\hline $\mathrm{T}$ & thead & torso $_{\text {tarms }}$ & $\mathrm{t}_{\text {shoulders }}$ & $\mathrm{t}_{\text {arm }}$ \\
\hline${ }^{\circ} \mathrm{C}$ & 36 & 34 & 34 & 33 \\
\hline $\mathrm{t}_{\text {forearm }}$ & $\mathrm{t}_{\text {hand }}$ & $\mathrm{t}_{\text {thigh }}$ & $\mathrm{t}_{\text {leg }}$ & $\mathrm{t}_{\text {feet }}$ \\
\hline 32 & 30 & 32 & 30 & 28 \\
\hline
\end{tabular}

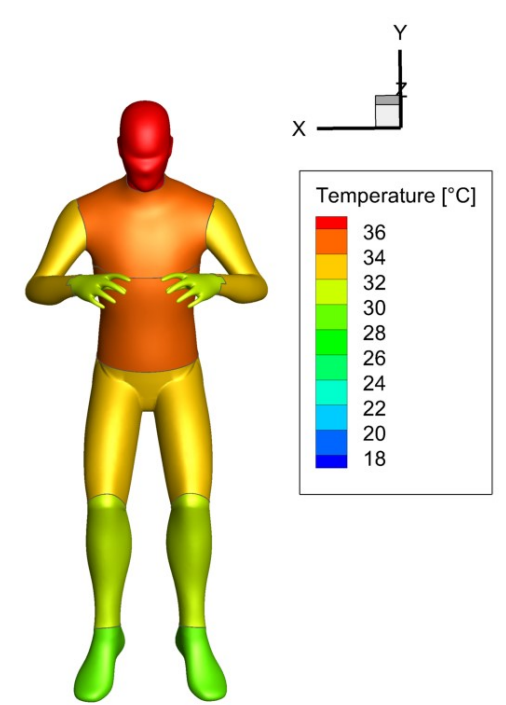

Fig. 3. Neutral body posture and temperatures imposed on the manikin surface.

We also imposed a reference temperature of $18^{\circ} \mathrm{C}$ for the internal volume and for the introduced air corresponding to the temperature in the common area (CCAA) of the Harmony module (Node 2). A temperature of $23^{\circ} \mathrm{C}$ has been incorporated for the walls, this is equivalent to a heat flux of $150 \mathrm{~W}$ in the Crew Quarter, corresponding to the heat flux generated by the electronic devices and other equipment present in the cabin. 


\subsection{Meshing and case data}

The mesh grid is composed of 9 million tetrahedral elements, the boundary layer consists of 5 layers on the inner surface of the CQ and we also added 5 boundary layers on the manikin surface (Fig. 4). The grid around the hands of the manikin is complex due to the realistic geometry. It is in this context that we decided to realize a grid independence test by using mesh refinement methods around the manikin hands. After we carried out a grid test for different refinement rates we observed an improvement of the convergence, so we decided to work with refined mesh around the hands (refinement ratio $=1$ ).

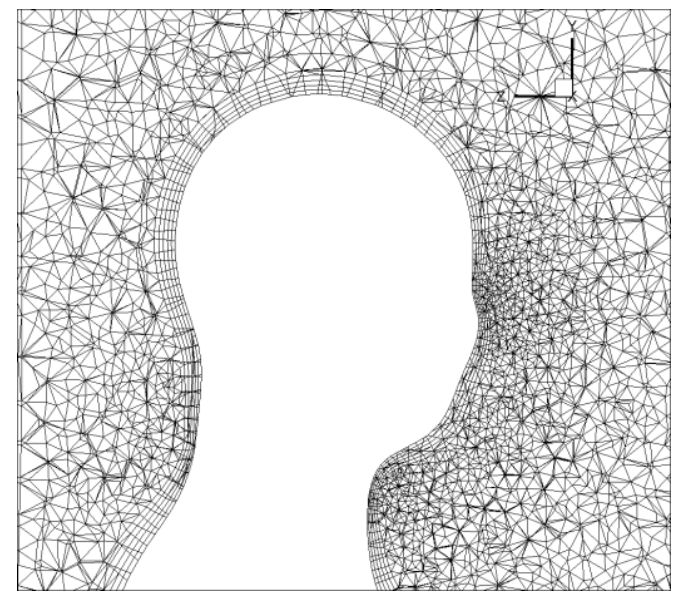

Fig. 4. Computational grid details along the manikin surface.

The turbulence model used for the numerical simulation was SST $\mathrm{k}-\omega$, to establish it we previously compared different turbulence models. The two most appropriate models were $\mathrm{k}-\varepsilon$ standard and $\mathrm{k}-\omega \mathrm{SST}, \mathrm{k}-\omega$ SST having a better convergence. This is consistent with previous research that has shown it to be an appropriate turbulence model for indoor air circulation [9].

As we said before, we compared two types of inlet distribution patterns, uniform and non-uniform (measured). The uniform velocity inlet was set at 0.432 $\mathrm{m} / \mathrm{s}, 0.552 \mathrm{~m} / \mathrm{s}$ and $0.624 \mathrm{~m} / \mathrm{s}$ corresponding to the air flow rates provided by de ventilation system, respectively 108,138 and $156 \mathrm{~m}^{3} / \mathrm{h}$. The inlet flow direction was unidirectional and perpendicular to the air diffusor. For each cases the outlet was defined as a pressure outlet with a rate of 1 .

Then, an important parameter in our simulations concerns the inclusion of micro-gravity. To take microgravity into account we disactivated the gravity in the operating conditions in Fluent. The simulation was run using the coupled pressure-velocity model and a second order discretization scheme.

\section{Results}

On board of the ISS NASA recommends for the internal atmosphere the following values [10]:
Temperature limits

- Comfort zone limits: $18-27^{\circ} \mathrm{C}$;

Ventilation flow rate

- Interior flow Uniformity: $66 \%$ of internal atmospheres must be between: $4.6-12 \mathrm{~m} / \mathrm{min}(0.076-0.2$ $\mathrm{m} / \mathrm{s})$.

Our goal was to determine if the CQs respect these recommendations (NASA Human Design Recommendations for the internal atmosphere of a space module). To observe the flow uniformity, we extracted velocity magnitude profiles for each simulation. And to observe the temperatures inside the CQ for the last simulations involving the heat flux generation from the manikin, we extracted temperature profiles. These profiles will be compared with each other in order to determine the influence of the flow rates for the three scenarios.

Figure 5 presents the distribution of the velocity magnitude in the coronal plane of the manikin for the three flow rates (columns) provided by the ventilation system and for the three cases (rows): 1-Uniform speed profile and isothermal manikin; 2-Measured velocity profile (real) and isothermal manikin; 3-Measured velocity profile and anisothermal manikin. It also presenting an iso-value of the velocity magnitude corresponding to $0.4 \mathrm{~m} / \mathrm{s}$ for the first row and $0.7 \mathrm{~m} / \mathrm{s}$ for the second and the third row. We set two different colors for the iso-surfaces of two last cases in order to differentiate them.

In order to determine the percentage of the volume respecting the requirements we integrated the volume meeting the requirements divided by the full volume of the CQ. We named volume respecting the requirements "Comfort zone". Figure 6 presents the evolution of this "comfort zone" in a frontal plane of the manikin for the three flow rates and the three cases. The frontal pane allows the analysis of the manikin's breathing zone. Firstly, by analysing the figure 5 and 7 we could notice that the global pattern of the flow inside the CQ is changing with the variation of the flow rate. Secondly and more importantly we observed a higher mixing of the air when using the real velocity profile (case 1 and 2) with an improvement of approximatively $6 \%$ but this does not allow to meet the requirements, because in the best case (real velocity profile with the higher flow rate, $156 \mathrm{~m}^{3} / \mathrm{h}$ ) we are only reaching $40 \%$ of internal atmosphere velocities between 0.076 and $0.2 \mathrm{~m} / \mathrm{s}$. One would have thought that the percentage would increase by increasing the flow rates, but that does not occur because the velocity quickly reach to high values, over the comfort zone. Lastly, we could observe (Figure 6) that the manikin's head is near the main air flow (discernable by the isosurface) but if the manikin's head would be a few centimeters forward a sensation of thermal discomfort could occur. 
1

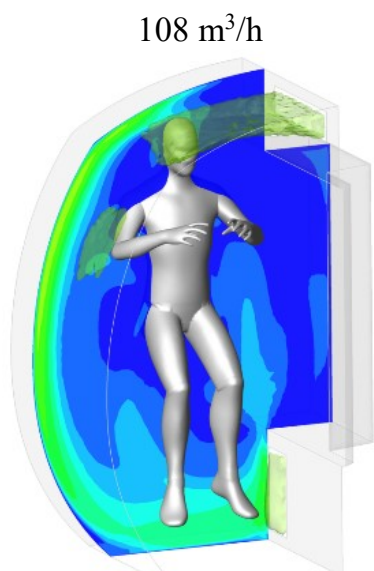

2

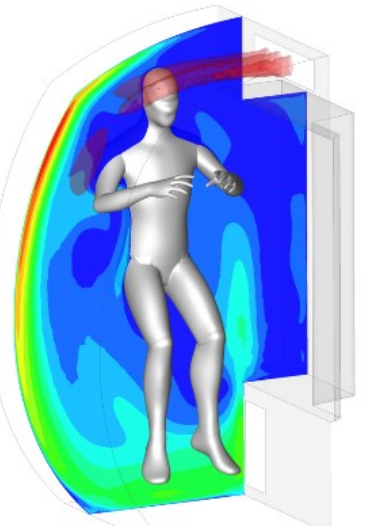

3

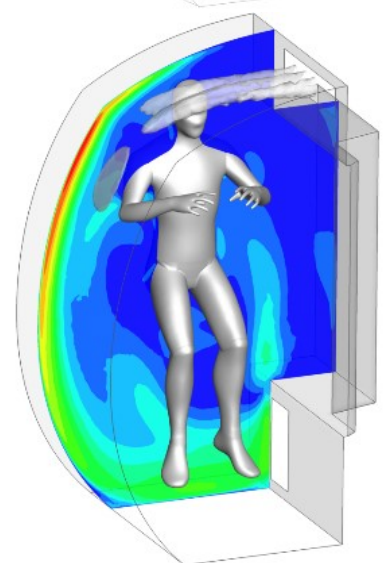

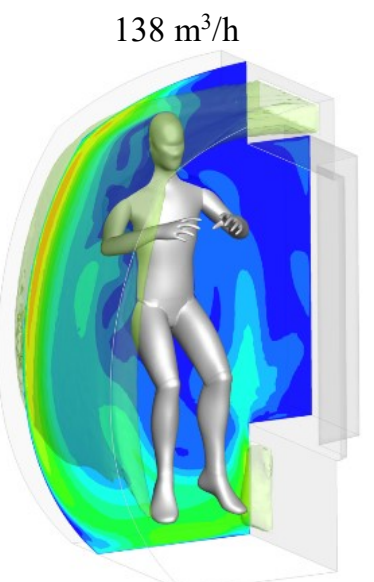
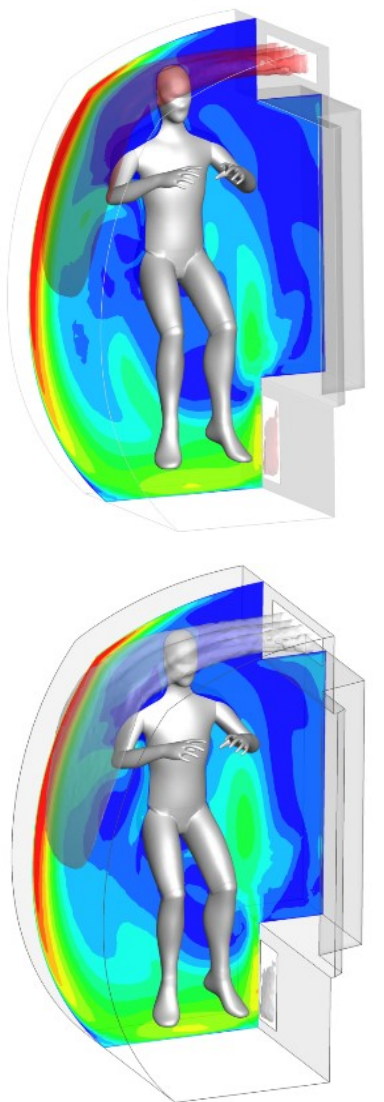
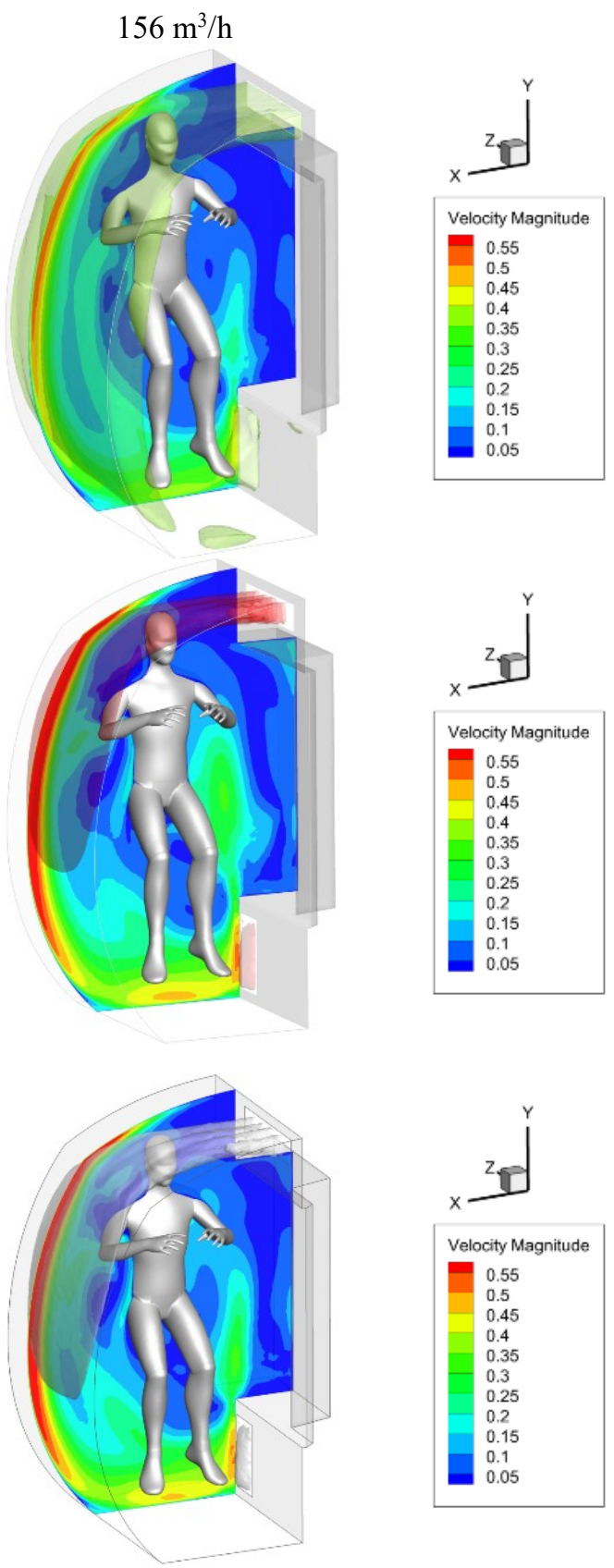

Fig. 5. Distribution of the velocity magnitude in the coronal plane of the manikin $[\mathrm{m} / \mathrm{s}]$.
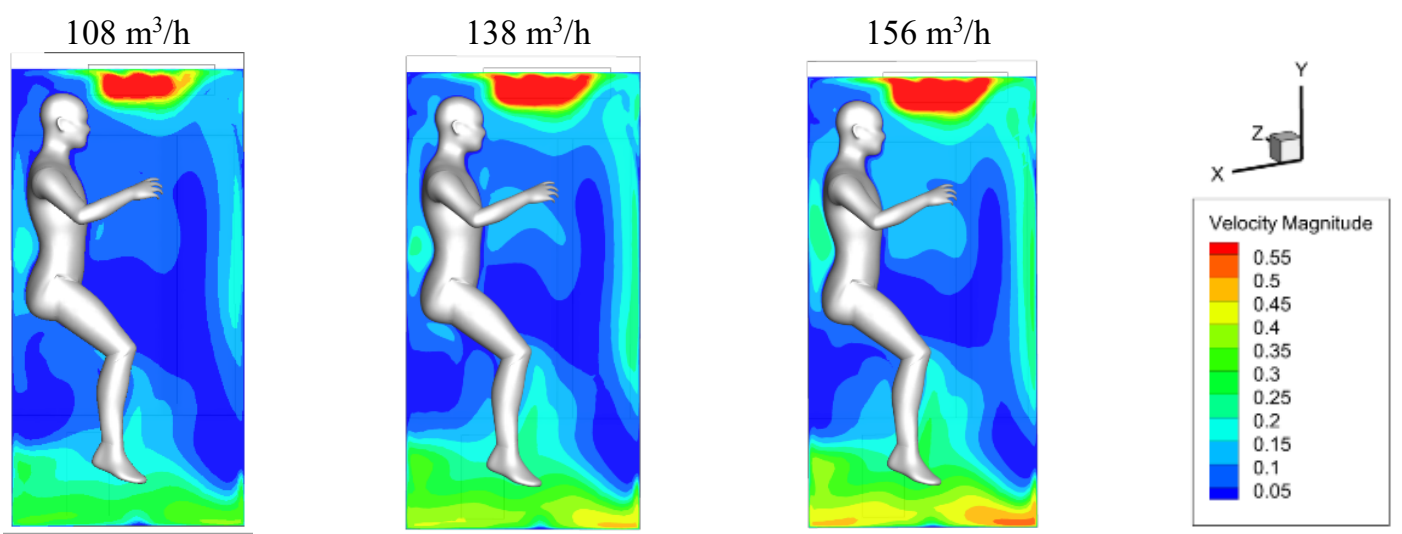

Fig. 6. Distribution of the velocity magnitude in the sagittal plane of the manikin for the third scenario $[\mathrm{m} / \mathrm{s}]$. 
$108 \mathrm{~m}^{3} / \mathrm{h}$

1

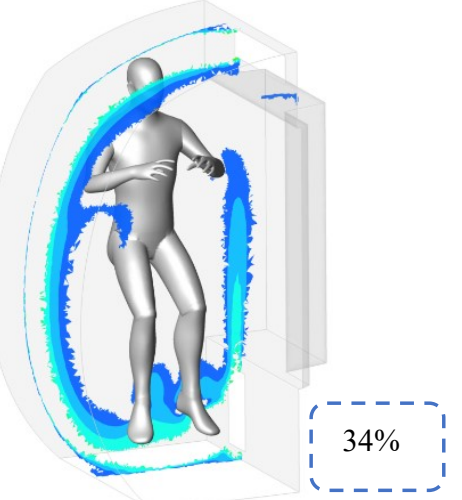

2

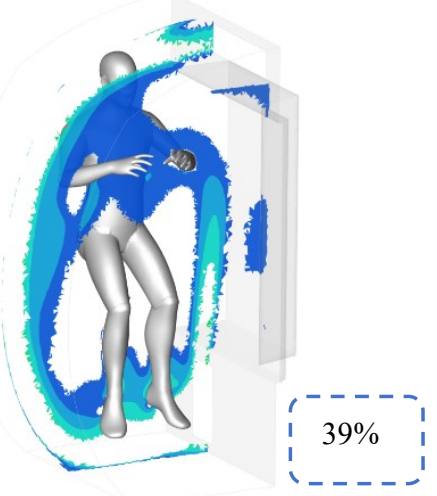

3

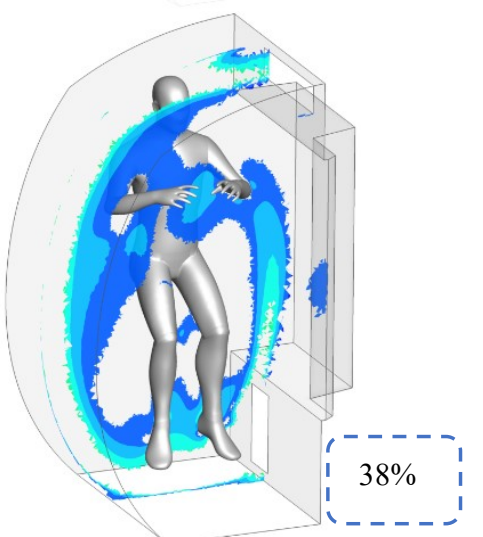

$138 \mathrm{~m}^{3} / \mathrm{h}$
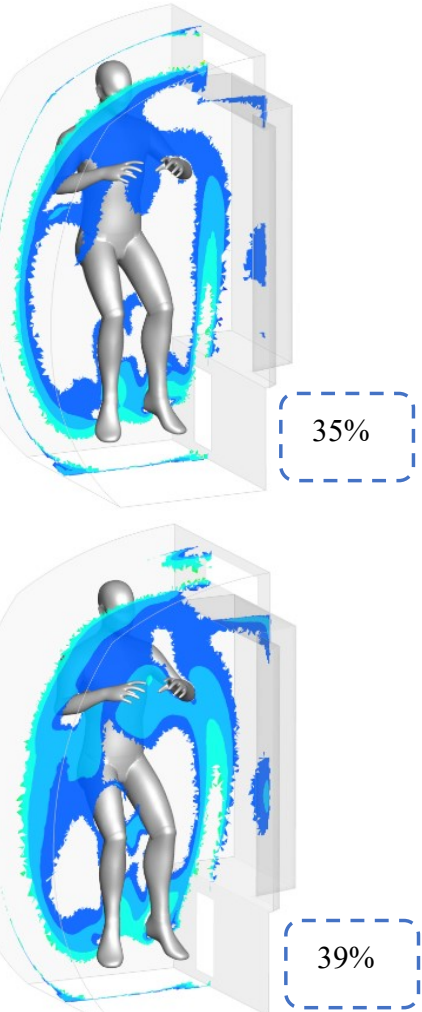

$156 \mathrm{~m}^{3} / \mathrm{h}$

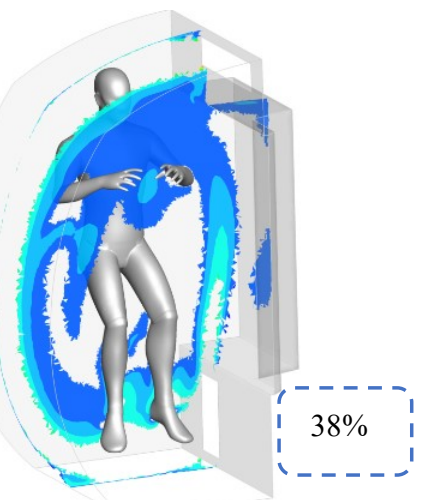

${ }^{2}$

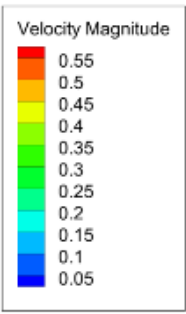

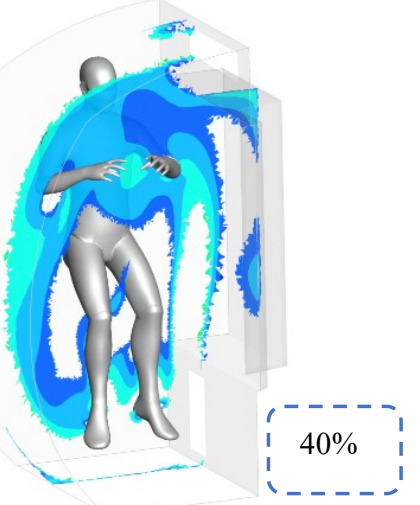
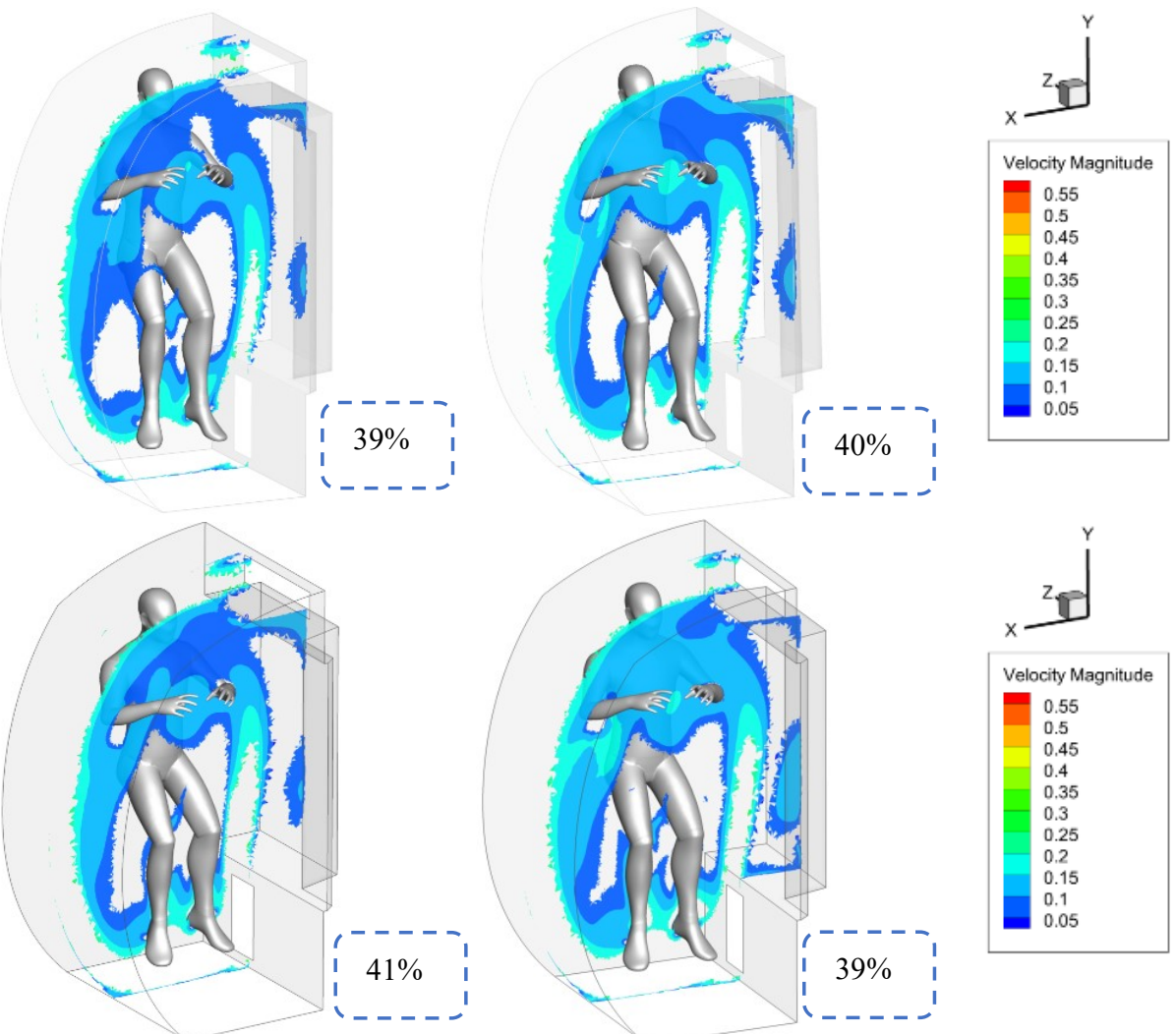

Fig. 7. Evolution of the velocity magnitude distribution respecting the requirements, "comfort zone" with percentage of the volume respecting the flow uniformity requirements $[\mathrm{m} / \mathrm{s}]$.
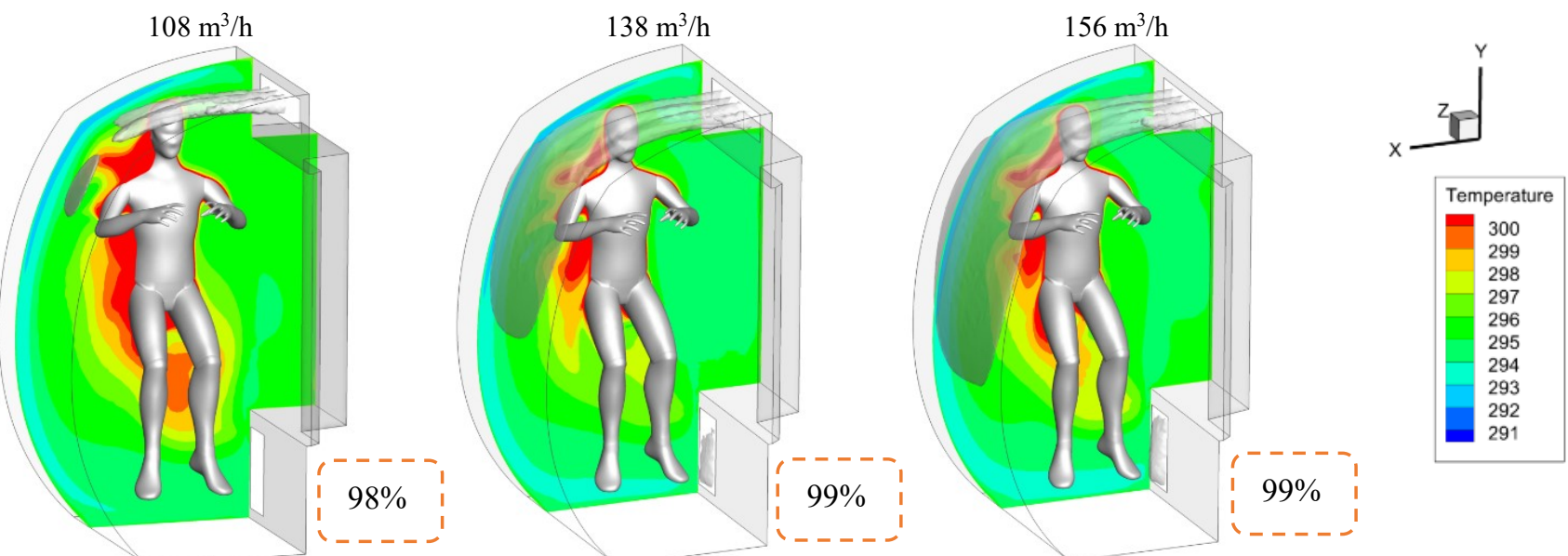

Fig. 8. Distribution of the temperature in the coronal plane of the manikin with percentage of the volume respecting the temperature requirements [ ${ }^{\circ}$ Kelvin]. 
Figure 8 shows the distribution of the air temperature in the coronal plane of the manikin for the three flow rates for the third case (Measured velocity profile and anisothermal manikin). We could observe an improvement of the air temperature for the two higher flow rates respectively 138 and $156 \mathrm{~m}^{3} / \mathrm{h}$. But despite a higher global air temperature the lower flow rate still allows a good thermal comfort inside the CQ.

\section{Conclusion}

This study helps us to understand the importance of considering the real velocity profile (non-uniform) instead of a uniform velocity profile. Results have shown that the real velocity profile create a higher mixing of the air leading to a better flow uniformity. We can thus conclude that an accurate representation of the inlet velocity profile is invaluable in obtaining accurate results.

Despite these uniformity improvements, requirements are still not met. While the "comfort zone" was situated around the astronaut's face in most cases, real life scenarios are hardly this simple. When taking into account personal comfort preferences and the fact that not all crew members sleep in the same position, we come upon a potentially risky scenario in which these personal preferences can have a negative impact upon the astronaut's health. It is important to realise that the bigger the comfort zone is, the greater the leeway crew members have.

In addition, we observed that velocity uniformity is not greatly influenced by the heat flux generated by the manikin. On the other hand, we observed that overall the temperatures requirements are met for the three flow rates.

Overall the current ventilation solution while being adequate for certain aspects, such as thermal comfort, tends to be lacklustre in others, such as air distribution. This last factor being important to the safety of the crewmembers warrants the study of improvements for the ventilation solution.

This work was supported by a grant of the Romanian Space Agency ROSA, QUEST - Advanced air diffusion system of the crew quarters for the ISS and deep space habitation systems, STAR-CDI-C3-2016-577.

\section{References}

1. Adams, C. Four Legs in the Morning: Issues in CrewQuarter Design for Long-Duration Space Facilities. 28th International Conference on Environmental Systems, Danvers, MA. (1998). https://doi.org/10.4271/981794

2. Broyan J. L. Jr. et al. International Space Station United States Operational Segment Crew Quarters On-orbit vs Design Performance Comparison. 39th International Conference on Environmental Systems, SAE International, Warrendale, PA. (2009). https://ntrs.nasa.gov/archive/nasa/casi.ntrs.nasa.gov/ $\underline{20130011142 . p d f}$
3. Broyan, J.L., S.M. Cady, and D.A. Welsh. International Space station Crew Quarters Ventilation and Acoustic Design Implementation. AIAA Journal. (2010). http://spacearchitect.org/pubs/AIAA-2010-6018.pdf

4. Schlesinger, T.P., B.R. Rodriguez, and M.A. Borrego, International Space Station Crew Quarters On-Orbit Performance and Sustaining Activities. AIAA Journal. (2013). https://ntrs.nasa.gov/archive/nasa/casi.ntrs.nasa.gov/ 20130011142.pdf

5. https://spaceflight.nasa.gov/gallery/images/station/cr ew-27/html/iss027e013105.html

6. Fairburn, S. and S. Walker, Sleeping With the StarsThe Design of a Personal Crew Quarter for the International Space Station., SAE Technical Paper. (2001).

https://www.researchgate.net/publication/28088003 0 'Sleeping_With the Stars' -

The Design_of_a_Personal_Crew_Quarter_for_th e International Space Station

7. K.W.D. Cheonga, W.J. Yua,, R. Kosonenb, K.W. Thama, S.C. Sekhara. Assessment of thermal environment using a thermal manikin in a field environment chamber served by displacement ventilation system. Building and Environment, Volume 41, Issue 12, December. (2006). https://doi.org/10.1016/j.buildenv.2005.06.018

8. Danca, P., et al., On the Possibility of CFD Modeling of the Indoor Environment in a Vehicle. Energy Procedia. 112: p. 656-663. (2017) https://doi.org/10.1016/j.egypro.2017.03.1133

9. Son C. H. et al, Investigation of Airflow and Accumulation of Carbon Dioxide in the Service Module Crew Quarters. 32nd International Conference on Environmental Systems, SAE International, San Antonio, TX. (2002). https://doi.org/10.4271/2002-01-2341 